
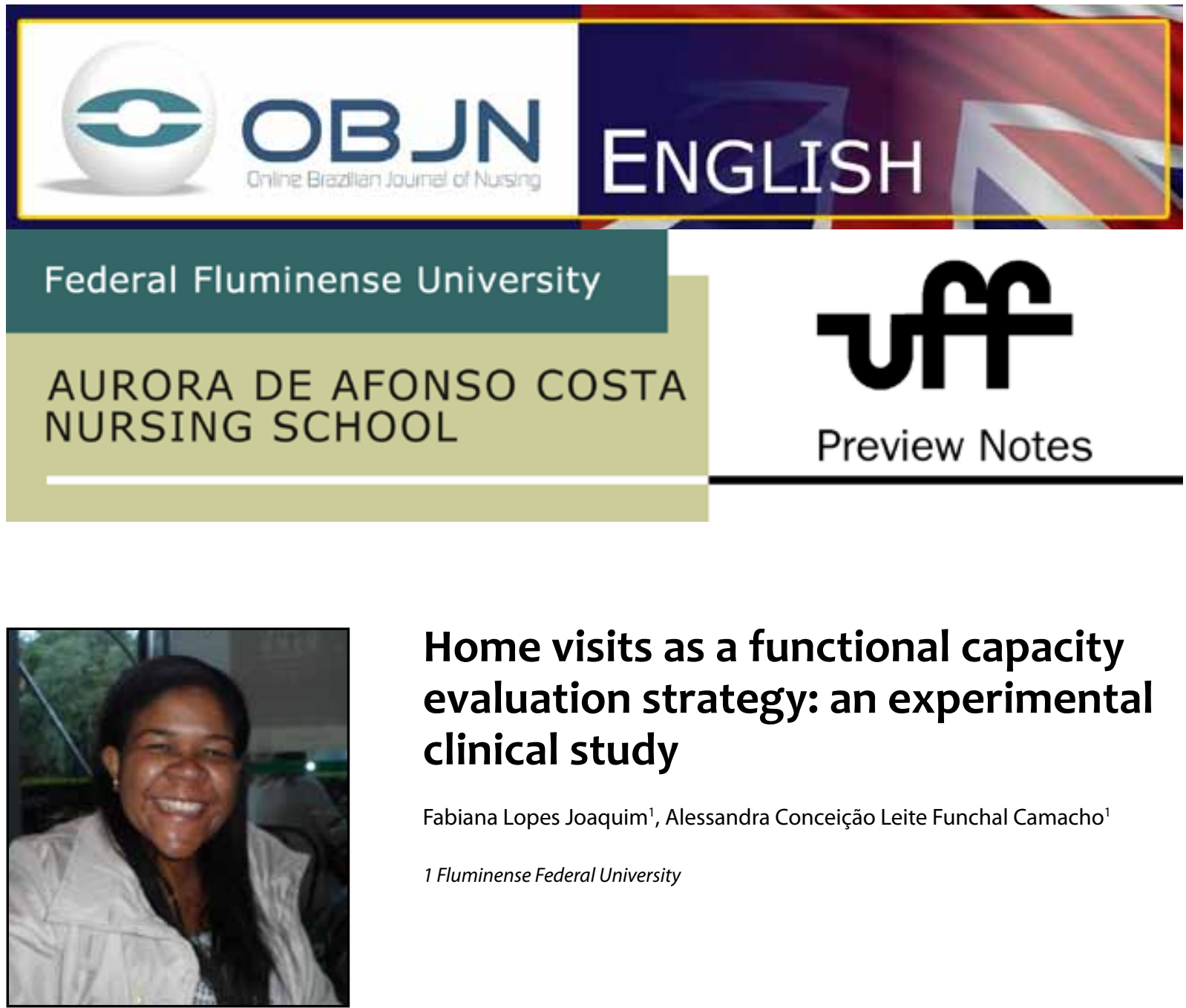

\title{
Home visits as a functional capacity evaluation strategy: an experimental clinical study
}

Fabiana Lopes Joaquim¹ , Alessandra Conceição Leite Funchal Camacho

1 Fluminense Federal University

\begin{abstract}
Aims: To analyze the functional capacity of patients regarding the care of venous ulcers by means of home visits; to compare the functional capacity between patients with venous ulcers who are, exclusively, going through outpatient therapy for wound healing, and those who are treated in the outpatient clinic and also receive home visits for continuing care. Methods: This is an experimental, randomized, non-blind and controlled clinical study, in which a quantitative approach was used. Scenario: outpatient clinic for wound healing of a hospital in Niterói, RJ and patients' homes. Subjects: adult and elderly patients suffering from venous ulcers in an outpatient clinic. For data collection we will use: Protocol I B Adapted - Assessment of patients suffering from venous ulcers (PROAP - UFF registered); KATZ-EIAVD scale; TINETTI Index and; the guidance instrument to be provided to the research subjects who receive home visits. For data analysis, the Mann-Whitney test (Wilcoxon rank-sum test) and descriptive statistics will be used.

Descriptors: Adult; Aged; Varicose Ulcer; Home Visit.
\end{abstract}




\section{PROBLEM SITUATION AND ITS SIGNIFICANCE}

Functional capacity is related to the condition that the individual presents with regard to living autonomously, and relates to the environment in which he lives. Therefore, performing an evaluation allows us to determine the independence of a person in terms of carrying out basic and instrumental activities.

Considering that functional capacity declines with age, it becomes necessary to develop strategies that are intended to promote, treat and rehabilitate the functional ability and social integration of individuals ${ }^{(1)}$. Based on these, and highlighting venous ulcers as an epidemiological problem that affects the lower limbs and impacts on the quality of life and productivity, it is necessary to evaluate the functional status of such patients. In this context, we include the home visit, pointed out by various studies as an opportunity to obtain additional information about the living conditions of the patients, their family dynamics, and their lifestyles. Therefore, it has been indicated as a factor associated with improvement in the quality of care provided to patients, as well as a contributor to the effective treatment of patients suffering from chronic diseases, since it minimizes costs and reduces the risk of infection ${ }^{(2-3)}$.

\section{GUIDING QUESTION}

Is the functional capacity of adults and seniors who suffer from venous ulcers influenced by household visits by a nurse?

\section{AIMS}

To assess the functional capacity in the care of venous ulcers in adult and elderly patients by means of home visits; to compare the functional capacity between adults and elderly patients who suffer from venous ulcers who attend an outpatient clinic for wound treatment and those who are treated in an outpatient clinic and who also receive home visits for continuing care.

\section{METHOD}

This is an experimental, randomized, non-blind, controlled clinical study, in which a quantitative approach is to be used.

The research scenario will comprise two fields of research: the outpatient clinic for wound treatment in a university hospital in Niterói/RJ, and the home of treated patients.

The subjects will be patients with venous ulcers who are undergoing treatment for their ulcers at an outpatient clinic and who meet the following inclusion criteria: adult and elderly patients suffering from venous ulcers in one or both lower limbs, who will consent to participate in the research and who have sufficient cognition to follow recommended guidelines during the study period. Exclusion criteria: patients suffering from arterial ulcers, diabetic foot, who are not able to adhere to the care and standards associated with the proposed care, and cannot attend the scheduled nursing visits continuously.

For data collection, the following instruments shall be-used: Protocol IB - Adapted - Assessment of clients suffering from venous ulcers (PROAP - UFF registered); Independence scale in Daily Life Activities (Katz - EIAVD Scale); Scale of evaluation of balance and gait (TINETTI Index); guidance instrument to be provided to the research subjects who receive home visits, explained by the author of the research. For data analysis, the Mann-Whitney test (Wilcoxon rank-sum test) and descriptive statistics will be used. The 
project was approved by the Ethics Committee in Research of the Faculty of Medicine, Fluminense Federal University, under the associated opinion No. 506,332, meeting the requirements established by Resolution No. 466 of December 12,2012 of the National Health Council/MS.

\section{REFERENCES}

1. Torres GV, Reis LA dos, Reis LA dos, Fernandes $\mathrm{MH}$, Alves $\mathrm{G}$ dos S. Avaliação da capacidade de realização das atividades cotidianas em idosos residentes em domicílio. Rev. baiana saúde pública. [Internet]. 2009 jul/sept [Cited 2013 Sept 18]; 33(3): 466 -75. Available from: http://inseer. ibict.br/rbsp/index.php/rbsp/article/view/227.

2. Ruschel KB, Azzolin KO, Rabelo ER. Home visits in cases of heart failure: reflection in the light of Leininger's theory. Online braz j nurs [Internet]. 2012 November [Cited 2014 Jan 28]; 11 (3): 88392. Available from: http://www.objnursing.uff.br/ index.php/nursing/article/view/3625.

3. Theile G, Kruschinski C, Buck M, Müller CA, Hummers-Pradier E. Home visits - central to primary care, tradition or an obligation? A qualitative study. BMC Fam Pract [Internet]. 2011 April [Cited 2013 Sept 18]; 12-24. Available from: http://www. biomedcentral.com/14712296/12/24.
Project Data: Dissertation project of the Academic Master of Science Program of Health Care, Fluminense Federal University.

All authors participated in the phases of this publication in one or more of the following steps, in According to the recommendations of the International Committee of Medical Journal Editors (ICMJE, 2013): (a) substantial involvement in the planning or preparation of the manuscript or in the collection, analysis or interpretation of data; (b) preparation of the manuscript or conducting critical revision of intellectual content; (c) approval of the versión submitted of this manuscript. All authors declare for the appropriate purposes that the responsibilities related to all aspects of the manuscript submitted to OBJN are yours. They ensure that issues related to the accuracy or integrity of any part of the article were properly investigated and resolved. Therefore, they exempt the OBJN of any participation whatsoever in any imbroglios concerning the content under consideration. All authors declare that they have no conflict of interest of financial or personal nature concerning this manuscript which may influence the writing and/or interpretation of the findings. This statement has been digitally signed by all authors as recommended by the ICMJE, whose model is available in http://www. objnursing.uff.br/normas/DUDE_eng_13-06-2013.pdf

Received: 01/23/2014

Revised: 03/23/2014

Approved: 03/23/2014 